\section{NEPAL SCHOOL OF SOCIOLOGY/ANTHROPOLOGY}

Dor Bahadur Bista

In Nepal, where tradition dominates so much of our lives, it is ironic that with regard to sociology and anthropology we have no tradition at all to follow, but only one to establish. This also makes our task relatively simple: all we have to do is make an honest effort without any pretensions, because we cannot be any better or worse than we really are. We must remember that in the field of sociology and anthropology we are starting with a clean slate. We have to admit with all humility that we do not know exactly what design will ultimately emerge. But that need not deter us from acting, because if we hesitate and fumble, others will make their advances.

We have already made two important beginnings: first, the decision to construct a single course of study for students of Sociology and Anthropology; and second, the decision to find a single professional association for Sociologists and Anthropologists. Thus the dye is already cast. All we have to do now is to apply our principles to the tasks at hand.

Nepal (compared to many other countries around the world) has had the unique advantage of developing the discipline of anthropology in a relatively short span of time. Until 1950, Nepal was isolated and inaccessible to outsiders except for peoples from adjacent and contiguous areas. So there was no way anthropology, which was primarily developed by Western societies during their colonial period, could have developed or been practiced in Nepal until scholars from Western societies were admitted into the country and allowed to conduct their studies. As a land with a multitude of linguistic, cultural and ethnic groups living in a relatively small land area, Nepal attracted Western scholars and students in increasing numbers from the 50 's up through the present.

All this activity has produced a considerable amount of literature, published mainly in the West in the form of journal articles, monographs, reports, and dissertations submitted to graduate departments of sociology and anthropology. Even though some of the reports and most of the dissertations do not ever appear or become accessible to Nepalese readers, they can nevertheless be read by serious students with a certain amount of initiative and effort. In addition to this, there is also quite a substantial ethnographic literature published in Nepal in English and Nepali, mainly by the teaching staff of the Panchayat Training Institutes, the Royal Nepal Academy, and many other Nepalese who are working in other sectors of the government or at the university.

Since materials written in Nepali are rarely read by foreigners, the fragmented nature of the reports available so far in Western languages has produced a very curious image of Nepalese in the eyes of Western people, something which is often reflected in the questions they sometimes ask about us. In other words, the separate, specialized studies do not add up to a general and composite picture of Nepalese society at large. Most of the works done so far talk only about one micro-situation or another, representing only a fragment of the total truth about Nepal. Some reports -- studies of the contact zones showing conflict or co-ordination -- also represent only a small area and depict localized small communities. None of these materials explain much that is useful and meaningful for the planning or administrative purposes of the country. Some of them, however, are useful for the development of the science of the discipline itself. There are anthropologists who consider that this is the limit of what anthropology can contribute, but this view is largely outdated. Anthropology can certainly study not only separate communities but also the process of integration among different ethnic groups and castes. Applied anthropology is a widely accepted discipline.

That anthropology in Nepal should "come of age" as in many developed countries around the world is obvious, as it serves two important functions. First, it promotes and defends the national culture and helps maintain the national identity of the country and its people. Second, it studies (to whatever possible extent) all the aspects of different Nepalese cultures, in addition to other outside cultures, and joins together the international 
community of social scientists for the promotion of science and for the broader cause of service to humanity. It is time that we share the burden and responsibility of the international community of anthropologists. This is what is meant by "coming of age". Nepalese anthropologists can certainly work towards the development of theoretical concepts, modes, paradigms, and processes based on their studies of the different aspects of Nepalese society and culture while acting as a catalyst in the process of national economic development.

Studies for the sake of science so far have been conducted mainly by foreign anthropologists. It seems that this will continue to be the case for some time to come. But what about the promotion and defense of our own national culture? This is what Nepalese anthropologists alone can do; outsiders can not be expected to do this. Nepalese anthropologist will have to study various societies at the micro-level before they can talk meaningfully about the promotion and defense of a national culture. The plural Nepalese society still needs to develop a composite culture acceptable to the majority, so that the Nepalese population can identify with it, and derive a sense of belonging, pride and satisfaction from it. This can happen only if all are given the freedom to play their own role without one dominating the other. The present competition and disorder among different ethnic, linguistic and religious groups cannot continue forever. It is unrealistic to expect that a single group could win out in all the spheres of language, religion, lifestyle values and material culture. The state will have to promote an integrative approach. This is where Nepalese anthropologists could play a very crucial role in the coming decades, and that is why I see the need for a Nepalese school of anthropology as not only obvious but absolutely essential. Nepalese anthropologists cannot continue to play the clownish role of an adjunct to an alien style of thinking nor remain a slave to sterile and outdated life-style. They will have to create their own little arena where the future of Nepal is taken constantly into consideration in their deliberations, writings, researche and publications. Kinship and marriage, religion and social control, as separate institutions, cannot occupy all our time forever.
Anthropology may need to maintain the tradition of western thinking for its own sake in some big-name universities. They can afford to do so. Their departments of anthropology usually are one among dozens of other disciplines and in a university which is one among several hundreds. As such, those scholars and graduate students, if counted among millions of graduates of their own society, are only an infinitely small and insignificant minority. But Nepalese graduates or scholars in anthropology are among the extremely privileged few who are expected to play very significant roles in their country, even when comparatively their number is just as insignificant as the number of scholars in the West. Imagine the burden of responsibility a Nepalese graduate of anthropology would shoulder in the continuing process of modernization of the country. This is not the case with most anthropologists of the industrially advanced and affluent societies of the world. Anthropologists from such societies should continue to conduct research for their own sake. A few individuals may even continue their Bohemian style. In contrast, the Nepalese graduates of sociology and anthropology can have very responsible jobs in the near future if they are encouraged to adopt a constructive attitude towards work, their society, and their training. By constructive attitude I mean a positive and future-oriented attitude in place of over-romanticized nostalgia, or an insecure and thoughtless mimicry of the West. Is it not obvious that we cannot really mimic and follow the style of thinking of our Western counterparts no matter how competent and qualified they themselves may be?

Qualified they all are. In technical fields or in hard sciences, which do not regard human sentiments and institutions as important, we can continue to be guided by the West in the future. But in areas involving human institutions, sentiments, values, and cultural behavior generally we cannot rely on or seek advice from our Western gurus and advisors beyond a certain limit. In generalizations and in abstractions oúr Western colleagues can still be very helpful. The best among them have had much broader and global perspective. But we cannot rely too much on an expert on one ethnic, regional, or caste group to forever advise courses of action. Nevertheless, we can complement each other if we carefully steer our courses of development in the field of anthropology. 
Hence the need for the Nepal school of anthropology is quite pressing. We will have to keep all of this in mind when we develop the curriculum for the Department of Sociology/Anthropology, as we will have to do this when the first group of undergraduate students finish their courses of study by the end of summer 1987. Unless we keep in mind the need of the country in coming years and the possible role our graduate students will be playing in shaping the future course of Nepalese society, it is possible that we will have provided a very outdated orientation and a useless nonfunctional education to our young people.

Departments of sociology and anthropology at some other universities may not be doing exactly what we want to do. So we may not be able to find a model anywhere. Visiting scholars or graduate students from outside cannot be models either. Their needs and values are different from ours. Our students will have to be strongly oriented towards the observation of the process and dynamics of emergent Nepalese society at an all encompassing level. This will be our Nepal school of anthropology. At this stage, we should not concern ourselves too much with whether or not our graduates will be recognized by one or the other famous universities around the world; that is not yet our priority. Anthropology in its application has always served the interests of the people who have used it. It began as a handmaiden of Western Christian missionaries, followed by colonial governments who used it quite extensively in many parts of the non-western and non-Christian world. In recent decades, applied anthropology has been used by U.N. agencies, WHO, World Bank, and international aid organizations for various types of development activities. Recently, it is also being used by industries and multinational corporations for sales promotions and production expansions.

Our priority at the moment is for graduates who understand the dynamics of Nepalese society and have the ability to project a better future for the people at the lower economic levels and provide a wider base for participation in the creation of a resilient and progressive national culture with a strong national identity. This will be Nepal's own school of anthropology.

\section{SOCIOLOGY AND ANTHROPOLOGY CURRICULUM AND THE NEEDS OF NEPAL}

Krishna B. Bhattachan

\section{I}

\section{Introduction}

Although sociology and anthropology emerged in the West during the first quarter of the nineteenth century, the disciplines entered Nepal only during the early 1950's at the research level and in 1981 at the teaching level, the latter in a combined form. Thus, sociology and anthropology; so rich and mature in theories and methods, is just five years old in Nepal. Until 1981, Sarana and Sinha's statement about the status of anthropology in Asia was correct: "To the best of our knowledge, anthropology has not been accorded independent academic recognition in Afghanistan, Pakistan, Nepal, and Bangladesh, although there are some anthropologists working in basically non-anthropological institutions" (1976:210).

In Nepal, however, the situation has changed since then. Sociology and anthropology are now taught at the Master's level at Tribhuvan University. A Master's level program is taught at the Kirtipur campus, and at four other campuses -- Pokhara, Kathmandu, Patan, and Biratnagar -- a B.A. level program has just been introduced. We must now evaluate our past performance and take stock of what we possess of sociology and anthropology curriculum, its relevance to the needs of Nepal, and future demands, needs, and priorities.

With these facts in mind, this paper will outline the development of the sociology and anthropology curriculum, critically review the current nature and the needs of Nepal, and discuss the problems and issues in curriculum development. 